\title{
De tanden in ARFID!
}

Citation for published version (APA):

Mulkens, S. (2019). De tanden in ARFID! Maastricht University. https://doi.org/10.26481/spe.20190412sm

Document status and date:

Published: 12/04/2019

DOI:

10.26481/spe.20190412sm

Document Version:

Publisher's PDF, also known as Version of record

\section{Please check the document version of this publication:}

- A submitted manuscript is the version of the article upon submission and before peer-review. There can be important differences between the submitted version and the official published version of record.

People interested in the research are advised to contact the author for the final version of the publication, or visit the DOI to the publisher's website.

- The final author version and the galley proof are versions of the publication after peer review.

- The final published version features the final layout of the paper including the volume, issue and page numbers.

Link to publication

\footnotetext{
General rights rights.

- You may freely distribute the URL identifying the publication in the public portal. please follow below link for the End User Agreement:

www.umlib.nl/taverne-license

Take down policy

If you believe that this document breaches copyright please contact us at:

repository@maastrichtuniversity.nl

providing details and we will investigate your claim.
}

Copyright and moral rights for the publications made accessible in the public portal are retained by the authors and/or other copyright owners and it is a condition of accessing publications that users recognise and abide by the legal requirements associated with these

- Users may download and print one copy of any publication from the public portal for the purpose of private study or research.

- You may not further distribute the material or use it for any profit-making activity or commercial gain

If the publication is distributed under the terms of Article $25 \mathrm{fa}$ of the Dutch Copyright Act, indicated by the "Taverne" license above, 
Sandra Mulkens

Faculty of Health, Medicine and Life Sciences

\section{De tanden in ARFID!}




\section{De tanden in ARFID!}

\section{Sandra Mulkens}

Geachte meneer de Pro-Rector, beste collega's en studenten, lieve vrienden en familie, zeer gewaardeerde toehoorders,

In de jaren tachtig ging ik met mijn ouders en broer elke zondag op bezoek bij oma en opa, vaak die van beide kanten. In beide huizen was er elke zondag vlaai, zoals dat in onze regio de gewoonte is. Bij één oma en opa was dat doorgaans vlaai van de bakker, maar de andere oma bakte zelf. Dat was de moeder van mijn moeder, Anna Brepols. Oma Brepols had tijdens de oorlog veel ontberingen doorgemaakt en verstond de kunst om van heel weinig toch iets te maken. Ze had beslist geen gat in de hand en bewaarde alles om het later nog eens te gebruiken. Daar hoorde ook bij dat ze de vlaai maakte van fruit en groente uit eigen tuin. Meestal was die vlaai erg lekker, bijvoorbeeld als er appels in waren verwerkt. Maar soms was er... rabarbervlaai. Ik vond hem afschuwelijk. De gekookte rabarber had zo'n weeïge, vieze smaak. Maar dat durfde ik niet tegen oma te zeggen. In plaats daarvan deed ik mijn uiterste best om, weliswaar met lange tanden, mijn bordje leeg te eten. Ik perste er daarna nog een 'lekker, oma!' uit, om haar niet voor het hoofd te stoten. Met als gevolg dat ik prompt nóg een stuk kreeg.

Het mechanisme daarachter leerde ik veel later kennen, tijdens mijn studie gedragswetenschappen: positieve bekrachtiging doet daaraan voorafgaand gedrag toenemen. Mijn oma was verheugd dat ik de vlaai schijnbaar zo lekker vond en vroeg niet eens of ik nog een stuk wilde, gastvrij als ze was. Ze kieperde, hup, nog een stuk op mijn bord: "Hier kind, er is genoeg en je moet goed eten!" En dan at ik het, kieskauwend doch met een glimlach, maar weer op.

Waarom vertel ik dit? Deels omdat ik op deze plek graag mijn oma en ook mijn peettante wil memoreren. Ze is helaas al 26 jaar dood en het rabarberverhaal heb ik haar nooit durven vertellen. En deels omdat het een aardig bruggetje is naar ARFID, het onderwerp van deze rede.

Vandaag aanvaard ik de bijzondere leerstoel Voedings- en Eetstoornissen. Deze leerstoel is ingesteld door SeysCentra, behandelcentrum voor kinderen met eetproblematiek en onzindelijkheid, en is ondergebracht bij de Faculteit Health, Medicine, and Life Sciences, aan deze universiteit.

Vandaag wil ik de gelegenheid grijpen om ARFID voor het voetlicht te brengen. Mijn doel is dat $u$ aan het eind van deze lezing weet wat ARFID is, waarom het een ernstig probleem is en wat de stand van zaken is met betrekking tot de behandeling ervan. Met andere woorden: dat ook ú ervan overtuigd bent dát, waaróm, en hóe de tanden in ARFID gezet dienen te worden! Ik streef ernaar dat mijn rede begrijpelijk overkomt; dat ook wie minder bekend is met onderzoek, diagnostiek en therapie straks weet waarover het ging. 
Waarschijnlijk weet $u$ al dat ARFID "iets met een eetprobleem te maken heeft", gezien mijn benoeming tot bijzonder hoogleraar 'Voedings- en eetstoornissen'. Sommigen durfden het ook te vragen in de aanloop naar vandaag: "Eh, wat is dat, de tanden in ARFID?" Anderen laten de uitleg vermoedelijk maar over zich heen komen. Weer anderen hebben het opgezocht op internet.

Allemaal prima! Zolang ARFID maar in de schijnwerpers staat en voortaan geen grote onbekende meer is! Want ARFID is een nieuwe ster aan ons firmament. Het is een nieuwe naam, beter gezegd een afkorting, voor een eetstoornis die overigens niet helemaal nieuw is.

Maar laat ik, voordat ik definitief mijn tanden zet in ARFID, u eerst even kort schetsen wat $u$ kunt verwachten vandaag.

Zo meteen ga ik u eerst uitleggen wat ARFID is door onder andere uit te leggen wat ARFID níét is. Zijn de criteria en achtergrond eenmaal duidelijk, dan bekijken we of ARFID een voedings- of een eetstoornis is, hoe vaak het voorkomt en wat de subtypes zijn. Tot slot ga ik in op de diagnostiek en behandeling van ARFID en sluit ik mijn rede af met het doen van enkele conclusies en aanbevelingen en mijn eigen plannen op dit gebied.

\section{Wat is ARFID niet?}

Als $u$ aan eetstoornissen denkt, is waarschijnlijk het eerste wat in u opkomt: anorexia nervosa. Onze aandacht wordt, onder andere door de media, heel erg gericht op dit soort extreme ziektebeelden. Anorexia nervosa is inderdaad een ernstige eetstoornis, die veel losmaakt en ook de meest dodelijke is van alle eetstoornissen (Hoek, 2006). Echter, van alle eetstoornissen komt anorexia nervosa het minst vaak voor (Lindvall Dahlgren, Wisting, \& Rø, 2017). Boulimia nervosa (de eetstoornis waarbij de betrokkene last heeft van eetbuien maar daarvoor compenseert door te braken of laxeermiddelen te gebruiken) en de eetbuistoornis (waarbij de betrokkene eetbuien heeft maar daarvoor niet compenseert, wat vaak leidt tot overgewicht) komen vaker voor en zijn in feite niet minder ernstig. Omdat personen die aan boulimia nervosa lijden meestal een normaal gewicht hebben (je ziet er niets van), is er veel verborgen leed. ARFID is iets anders dan anorexia nervosa, maar er zijn wel raakvlakken. Mensen die lijden aan anorexia nervosa hebben ondergewicht en een grote angst om te eten, vanwege een hevige angst om aan te komen en daarover geen controle te hebben. Zij proberen dit 'niet aankomen' voor elkaar te krijgen door ofwel structureel heel weinig of selectief te eten, ofwel door maatregelen te nemen om zich van de gegeten calorieën te ontdoen, bijvoorbeeld door te purgeren (overgeven of laxeermiddelen gebruiken) (DSM-5; American Psychiatric Association, 2014). Niet of selectief eten hebben anorexia nervosa en ARFID met elkaar gemeen, en ook bij ARFID kan er sprake zijn van ondergewicht. Echter, bij ARFID is er geen sprake van angst om aan te komen in gewicht en om de controle te verliezen over eten en gewicht. Er is bij ARFID geen probleem met het lichaamsbeeld. 
ARFID is ook niet alleen maar 'moeilijk eten' of allerlei eten 'niet lusten'. Wie jonge kinderen heeft, herkent wellicht het voedselgevecht met spinazie, broccoli of champignons. Geschat wordt dat $25-45 \%$ van de kinderen tussen 2 en 5 jaar problemen heeft met eten/voedselweigering, maar de meerderheid groeit daar doorgaans overheen (Mayes, Volkmar, Hook, \& Cicchetti, 1993; Nederlands Centrum Jeugdgezondheid, 2017). Sterker: gemiddeld zijn zeven proefsessies nodig om aan nieuw eten te wennen, of om te kunnen beslissen of je het eten al dan niet lust. De hoeveelheid sessies is afhankelijk van de leeftijd van het kind en het type eten (zie bijvoorbeeld: Birch \& Marlin, 1982; Horne et al., 2004).

\section{De vele gezichten van ARFID}

ARFID staat voor 'avoidant/restrictive food intake disorder'. In het Nederlands klinkt dit eetprobleem evenwel nog langer, namelijk 'vermijdende/restrictieve voedselinnamestoornis' (APA, 2014). Dat valt al helemaal niet goed af te korten. VRVIS 'bekt gewoon niet zo lekker' als ARFID. Wat de term beoogt aan te duiden is: iemand vermijdt eten en/of beperkt zich tot het eten van bepaalde voeding, en dat veroorzaakt problemen. Aan de hand van onderstaande zes casussen wil ik een duidelijker beeld schetsen van ARFID.

De 3-jarige Marie is te vroeg geboren en heeft altijd een sondeslang gehad. Ze heeft nooit geleerd oraal te eten. Haar ouders hebben van alles geprobeerd om haar zover te krijgen, maar het lukt hen niet. Marie weigert via de mond te eten. Ze houdt gewoon haar kaken op elkaar of begint te kokhalzen. Haar ouders zijn ten einde raad, wanneer zij aankloppen bij de kinderarts. 'Marie krijg geen hap door de keel'.

Roy is 7. Hij houdt van voetbal, maar kan niet goed meetrainen. Hij voelt zich vaak te zwak en te duizelig. Dat komt omdat hij te weinig eet. Eigenlijk heeft hij nooit honger. Nooit gehad ook. Hij zou vergeten te eten als zijn ouders hem niet steeds hielpen herinneren. Als hij iets eet, zit hij bovendien al snel 'vol'. Volgens de arts groeit hij onvoldoende en mist hij ook belangrijke voedingsstoffen. 'Roy heeft er de buik van vol'.

Sanne is 13 jaar en altijd een moeilijke eter geweest. Door de jaren heen werd het keuzepalet aan voedingsmiddelen die zij wilde eten steeds kleiner. Beigebruin en krokant, dat is zowat het enige wat Sanne verdraagt. Dat betekent in de praktijk: friet, kipnuggets en kroketten. Haar ouders koken apart voor haar en zijn al blij wanneer ze in ieder geval iets eet. Inmiddels heeft Sanne echter behoorlijk overgewicht ontwikkeld. Op het oog lijkt ze 'een lekkerbek', maar niets is minder waar.

Johan is 18 jaar en heeft een autismespectrumstoornis. Eten gaat goed zolang het in zijn mond oké aanvoelt. Voedsel met een vreemde smaak, kleur of bite gaat er niet in. Hij zal niet snel iets nieuws proberen. Sinds kort studeert hij. Zijn eetgewoonten zorgen voor grote problemen: thuis, op school en met zijn vriendin. 'Wat Johan niet kent, dat eet 'ie niet'. 
Bo is 25 . Ze eet alleen maar rauwe, extreem gezonde dingen en is heel bang voor eten dat niet biologisch geteeld is. Dat eet ze niet, omdat zij denkt dat het haar ziek zal maken. Inmiddels mist zij essentiële voedingsstoffen en is zij erg afgevallen. Haar BMI is nog maar 17. Voor Bo zelf is haar eetpatroon evident. 'Dat is het hele eieren eten'.

Ria (40 jaar) was altijd een redelijk normale eter. Exotische ingrediënten vermeed ze wel, maar dat was nooit een echt probleem. Op vakantie nam ze haar eigen eten mee. Wel was ze altijd wat bezorgd aangelegd. Als er iets speelde, reageerde zij lichamelijk: 'ze kon geen hap door de keel krijgen'. Een tijd geleden verslikte zij zich in een tuinboon. Het leek alsof ze stikte. Omdat ze deze enorm angstige ervaring nooit meer wil meemaken, eet ze sindsdien alleen nog maar vloeibaar voedsel: milkshakes, appelmoes, pap, maaltijdsoep, gepureerd eten. Uit eten gaat ze niet meer. Ze voelt zich ook steeds somberder en eenzamer. Voor Ria geldt: 'Slikken, of stikken'.

Deze casussen passen allemaal bij ARFID en tonen de vele gezichten van dit eetprobleem. Hoe zit dat nu precies? ARFID is pas in 2013 als diagnose opgenomen in het handboek waarin de psychische stoornissen staan beschreven, de DSM ofwel de 'Diagnostic and Statistical Manual of Mental Disorders'. Wij gebruiken dit handboek om allerlei problematisch gedrag te diagnosticeren en te classificeren, met als doel een gezamenlijke taal en uiteindelijk beter begrip van deze problemen en hoe deze te onderzoeken en behandelen.

In 2013 verscheen de DSM-5, de nieuwste uitgave van ons diagnostische handboek, 6 jaar nadat de DSM-5 'werkgroep Eetstoornissen' was gestart met de herziening van de DSM-IV categorieën 'voedingsstoornissen' en 'eetstoornissen'. Aan deze werkgroep namen 12 deskundigen deel, onder wie één Nederlander, psychiater Hans Wijbrand Hoek. De DSM-5 beschrijft de volgende voedings- en eetstoornissen: Anorexia nervosa, Boulimia nervosa, Eetbuistoornis, Pica, Ruminatiestoornis, ARFID, Andere gespecificeerde voedings- of eetstoornis, en de Ongespecificeerde voedings- of eetstoornis.

\section{De DSM-5 criteria voor ARFID zal ik toelichten:}

A) lemand eet te weinig (restrictief) en/of te selectief, hetgeen ingrijpende gevolgen heeft voor de lichamelijke en/of de psychosociale gezondheid. Te weinig en/of selectief eten kan namelijk zorgen voor gewichtsverlies, groeiproblemen, voedingstekorten, uitdroging, de noodzaak van sondevoeding of bijvoeding, vermoeidheid en uitputting, maar ook tot concentratie- en denkproblemen of sociale isolatie.

De DSM-5 noemt daarbij een aantal subtypes: het probleem kan bijvoorbeeld komen door:

(1) een gebrek aan interesse in eten of voedsel, of de patiënt vermijdt bepaald voedsel,

(2) vanwege bepaalde kenmerken van het voedsel (zoals kleur, vorm of hoe het aanvoelt in de mond),

(3) of de patiënt is bang voor de negatieve gevolgen van het eten (zoals overgeven of stikken). 


\section{B) Het onvoldoende of weinig gevarieerde eten komt niet doordat er onvoldoende eten voorhanden is -}

bijvoorbeeld bij schaarste of armoede - of wanneer er in een bepaalde cultuur specifieke eetgewoontes zijn.

C) Het probleem past niet bij anorexia of boulimia nervosa en de patiënt ervaart geen probleem met zijn lichaamsgewicht of -vorm. Dat wil zeggen dat de ARFID-patiënt niet bang is om in gewicht aan te komen.

D) De eetstoornis is niet het gevolg van een lichamelijke aandoening. En wanneer er wel ook een lichamelijk probleem is, dan is het eetprobleem duidelijk ernstiger dan je hierbij zou verwachten.

Voordat ARFID in 2013 zijn intrede deed in ons diagnostische handboek, bestond het probleem vanzelfsprekend ook al. Het werd alleen anders genoemd én men dacht dat het probleem uitsluitend bij kinderen voorkwam. Zo beschreef de voorganger van de DSM-5, de DSM-IV, Voedings- en eetstoornissen op zuigelingen- of vroege kinderleeftijd en hanteerde daarbij de volgende criteria:

- Voedingsstoornis waarbij betrokkene er nooit in slaagt voldoende te eten met een in significante mate uitblijven van gewichtstoeneming of een significant gewichtsverlies gedurende ten minste één maand.

- Het gedrag is niet het gevolg van een bijkomende maag-darmziekte of een somatische aandoening

- De stoornis is niet eerder toe te schrijven aan een andere psychische stoornis of door een tekort in beschikbaar voedsel.

- Het begin ligt vóór het zesde jaar.

Ten opzichte van de DSM-IV heeft de DSM-5 een aantal voordelen. Dit illustreer ik aan de hand van mijn eerdere casuïstiek. Volgens de oude editie (DSM-IV) konden alleen Marie en Roy gediagnosticeerd worden met een eetprobleem. De andere casussen - met overgewicht, ouder dan 18, of met een latere start dan 6 jaar, zoals Sanne, Bo, Johan en Ria - waren niet bij een eetprobleem onder te brengen, tenzij bij een 'eetstoornis niet anders omschreven', de vergaarbak van eetproblemen die nergens goed bij passen. Ria zou wellicht de diagnose 'specifieke fobie: angst om te stikken' hebben gekregen. De criteria in de DSM-IV bleken dus te vaag, maar ook te smal. Er is dan ook weinig onderzoek gedaan naar deze stoornis. De nieuwe, uitgebreidere criteria in DSM-5 bieden ons meer mogelijkheden, nu de ontstaansleeftijd ook na de kinderleeftijd kan liggen (Ria) en er geen associatie met ondergewicht hoeft te zijn: er kan sprake zijn van normaal gewicht (bijvoorbeeld als gevolg van sondevoeding) en zelfs overgewicht (Sanne).

Dat klinkt heel mooi en dat is het ook. Echter, de DSM wordt gebruikt om psychische stoornissen, zoals eetstoornissen, te classificeren. Problematisch bij ARFID is dat er een grote somatische component in zit of kan zitten. De lichamelijke problemen vallen het meest op en worden vaak gezien als het meest ernstig. Om te constateren of er sprake is van ARFID is het inderdaad van belang dat de eetproblemen niet beter 
worden verklaard door een gelijktijdig optredende lichamelijke aandoening. En wanneer de eetstoornis zich voordoet binnen de context van een andere aandoening of stoornis, is het van belang te signaleren of de ernst van de eetstoornis groter is dan wat normaal bij deze aandoeningen of stoornissen wordt gezien en of afzonderlijke aandacht gerechtvaardigd is. Voedselweigering kan dus, behalve als ARFID-criterium, ook worden gezien als een symptoom vanuit een medisch perspectief. De kinderarts speelt een belangrijke rol als het gaat om vroege opsporing, opstellen van verwijzingscriteria, diagnostiek, behandeling en follow-up van kinderen die zich presenteren met afwijkend voedingsgedrag. Om onderscheid te kunnen maken tussen diverse soorten eetproblemen en eetstoornissen op diverse kinderleeftijden zijn in het verleden een aantal classificaties ontwikkeld, zoals de kindergeneeskundige indeling van Kindermann en Kneepkens (2010), de Wolfson-criteria (door kinderartsen met specialisatie maag-, darm- en leverziekten; Levy et al., 2009), de DSM-IV-criteria (APA, 2000), de DC:0-3R en DC:0-5 (Zero to Three, 2005, 2017), en de Great Ormond Street Hospital Criteria (Bryant-Waugh, 2000; Lask \& Bryant-Waugh, 2000).

Het nadeel van alle classificatiemethoden is dat het eetprobleem steeds aan (een fase van) de kinderleeftijd gekoppeld wordt, maar ook dat er zoveel verschillende methoden zijn. Met de komst van DSM-5 beschrijven we het eetprobleem ARFID op één allesomvattende manier, is de leeftijdsrestrictie losgelaten en kan ARFID ook gediagnosticeerd worden op latere leeftijd, bijvoorbeeld als gevolg van een traumatisch voorval. Artsen zijn dan ook blij met de komst van ARFID, zodat we samen door één bril naar een problematiek kunnen kijken die verder gaat dan somatiek en ook verder dan de kinderleeftijd.

Ook SeysCentra, het behandelcentrum dat mijn leerstoel heeft ingesteld, kent het probleem al lang, dat wil zeggen lang voordat het in de DSM-5 als ARFID werd omschreven. Daarvoor duiken we even in de geschiedenis. Orthopedagoog Daniel Seys en psycholoog Pieter Duker ontwikkelden in samenwerking met de Radboud Universiteit Nijmegen vanaf 1970 behandelmethodieken voor probleemgedrag bij mensen met een verstandelijke beperking. In 1980 klopten de ouders van een kind van 3 jaar dat gevoed werd via een buiksonde bij hen aan met de vraag: kunnen jullie misschien ons kind leren eten? De behandeling van Seys en Duker duurde 3 maanden. Daarna had het kind geen sonde meer nodig. Seys en Duker hadden op dat moment geen ervaring met het behandelen van deze vorm van voedselweigering. Hun kennis van gedragstherapeutische principes en klinische intuïtie bleek voldoende. Het behandelteam werkte vervolgens verder aan de ontwikkeling en validatie van een uniek 12-stappenplan voor zware eetproblemen bij kinderen. Dat plan ligt ten grondslag aan de huidige succesvolle behandeling, die we het SLIK-programma noemen (Dumont et al., in druk; Seys, Dumont, van Meerten, Rensen, \& Duker, 2014). Door de jaren heen is de eetkliniek van SeysCentra uitgegroeid tot een landelijk expertisecentrum met een last-resort-functie.

Tot zover over achtergrond en verleden van ARFID. We kunnen constateren dat ARFID bekendstond onder veel verschillende namen, die aan de hand van allerlei verschillende afstreeplijstjes werden bepaald, maar dat we nu orde moeten scheppen in de chaos. ARFID is een goede naam voor een ernstig eetprobleem dat 
verder gaat dan een lichamelijk probleem of een kinderprobleem en dat - gelukkig - net als tal van andere psychische problemen, zoals angststoornissen en andere eetstoornissen, behandeld kan worden.

\section{Maar: is ARFID nou een voedingsstoornis of een eetstoornis?}

Net als Rachel Bryant-Waugh en Jennifer Thomas, twee kopstukken op het gebied van ARFID, ben ik van mening dat het niet moet uitmaken of ARFID een voedingsstoornis of een eetstoornis wordt genoemd. Het feit dat ARFID in het verleden een voedingsstoornis werd genoemd, die vooral bij kinderen onder de 6 jaar voorkwam - die vaak nog gevoed moesten worden - lijkt ervoor te pleiten om ARFID een voedingsstoornis te noemen. Ook al om het onderscheid te verduidelijken met zogenoemde 'klassieke eetstoornissen' als anorexia nervosa, boulimia nervosa en eetbuistoornis, eetstoornissen waarbij tevens sprake is van een probleem met het lichaamsbeeld. Echter, het feit dat ARFID veel meer is dan problemen met gevoed worden dan wel eten, en ook voorkomt bij mensen boven de 6 jaar, plus het feit dat een groot deel van de ARFID-populatie bang is om te eten (maar om een andere reden dan bij de klassieke eetstoornissen het geval is), plus het feit dat ARFID kan overgaan in een andere eetstoornis, zoals AN, pleiten ervoor om ARFID een eetstoornis te noemen. Het kan dus beide en laten we het ook zo doen: ARFID is een voedings- of eetstoornis, net zoals anorexia nervosa, boulimia nervosa, eetbuistoornis, pica, ruminatiestoornis, andere gespecificeerde voedings- of eetstoornis, en de ongespecificeerde voedings- of eetstoornis.

Binnen de voedings- of eetstoornis ARFID kunnen volgens de DSM-5 verschillende subtypen worden onderscheiden, namelijk:

1. Het type waarbij de patiënt een schijnbaar gebrek aan interesse in voeding en eten heeft. Deze mensen zitten meestal snel vol.

2. Het type waarbij de vermijding gebaseerd is op de sensorische eigenschappen van voedsel (hoe het aanvoelt). Deze symptomatologie wordt vaak gezien bij kinderen met een autismespectrumstoornis.

3. Het type waarbij de vermijding gebaseerd is op angst voor vervelende gevolgen van eten (angst voor pijn, slikken, stikken, kokhalzen, overgeven). In deze groep vinden we ook kinderen die in hun vroege jeugd als gevolg van complexe medische problematiek negatieve voedingservaringen hebben opgedaan: ze hebben pijn, misselijkheid of benauwdheid ervaren tijdens of na het voeden. Voorts kan het doormaken van een verslik- of bijna stikincident posttraumatische stressklachten tot gevolg hebben en ertoe leiden dat men uitsluitend nog vloeibare voeding accepteert.

Ofschoon er nog onvoldoende ondersteuning is voor het onderscheiden van deze specifieke subtypen en hun eventueel verschillende oorzaken, zijn daar wel hypothesen over opgesteld. Zo hebben Thomas en collega's (2017) een driedimensionaal model ontworpen om deze drie ARFID-presentaties te begrijpen, 
waarbij zij speculeren over mogelijke onderliggende neurobiologische afwijkingen, bijvoorbeeld betreffende eetlust en zintuiglijke waarneming. Dit zou volgens de auteurs implicaties hebben voor de behandeling: een patiënt met ARFID van het type 'gebrek aan interesse' zou in hun optiek mogelijk een andere behandeling nodig hebben dan een patiënt die vooral bang is voor de gevolgen van het eten. Deze veronderstellingen zijn aannemelijk, maar nog niet onderzocht. Terugkijkend naar de casussen lijkt zowel Marie als Ria te passen binnen ARFID-subtype 3, de categorie waarbij er angst is voor de gevolgen van eten. Roy heeft geen interesse in eten (subtype 1), en Sanne en Johan passen bij het sensorisch gevoelige type, waarbij al dan niet een autismespectrumstoornis een rol zou kunnen spelen (subtype 2).

Bo lijkt een geval apart te zijn. Ze eet extreem gezond, neemt alleen rauw en biologisch geteeld voedsel tot zich en is bang anders ziek te worden. Wellicht komt nu bij sommigen van u de term 'orthorexia nervosa' naar boven. Orthorexia wordt omschreven als een psychische stoornis met een obsessie voor biologisch, puur en gezond eten. Deze leidt tot het beperken van veel verschillende soorten voeding, met als gevolg gewichtsverlies en ondervoeding. Daarbij komt een intense angst voor bewerkt of ongezond eten. Deze term is veel in het nieuws geweest en was onlangs onderwerp van een documentaire. De maakster en een deel van de geïnterviewden waren het erover eens dat de symptomen van deze 'eetstoornis' ernstig zijn en dat een nieuwe eetstoornis met bijbehorende behandeling gerechtvaardigd zou zijn. Natuurlijk klinkt dit gedrag niet gezond en de link met een eetstoornis is dan ook snel gelegd. Echter, in de DSM-5 staan legio mogelijkheden om een dergelijke stoornis te diagnosticeren. Daarbij kan er gekeken worden in de hoek van de dwangstoornissen, maar ook bij bepaalde persoonlijkheidsstoornissen en zeker ook bij de bestaande eetstoornissen. Maar sterker nog, in de DSM-5 kan Bo's problematiek ook worden ondergebracht bij de diagnose ARFID. De belangrijkste kenmerken van deze eetstoornis heb ik u getoond: het vermijden van voedsel vanwege bezorgdheid over de aversieve gevolgen van eten (ongezond worden), die blijkt uit een aanhoudend niet voorzien in de eigen voedings- en energiebehoeften, samenhangend met een (of meer) van de volgende kenmerken:

- significant gewichtsverlies;

- significante voedingsdeficiëntie;

- afhankelijkheid van sondevoeding;

- een duidelijk interfereren met het psychosociale functioneren.

Tenzij Bo of een vergelijkbare patiënt toch graag wilde afvallen - vanuit angst om dik te worden of vanwege zorgen rondom het lichaamsbeeld - zou haar problematiek eerder bij een vorm van anorexia of boulimia passen, of mogelijk binnen een restcategorie. Maar mensen met zogenaamde 'orthorexia nervosa', wier eetpatroon als voornaamste doel heeft om 'gezond te zijn' (en dus niet om lichaamsvormen of gewicht te beïnvloeden), kunnen ook met een ARFID-diagnose een goede behandeling krijgen. Kortom, er is voor casussen als die van Bo geen behoefte aan weer een nieuwe eetstoornis. 


\section{Hoe vaak komt ARFID voor?}

We weten nog niet precies hoe vaak ARFID voorkomt, aangezien de diagnose met de nieuwe criteria nog zo vers is. Maar er kan er wel iets over gezegd worden. Voordat ARFID als diagnose bestond, schatte men dat bij 3-10\% van de kinderen de voedingsproblemen ernstig waren, aanhielden en zelfs over de tijd ernstiger werden (Kerwin, 1999). Ernstige voedingsproblemen komen vaker voor bij kinderen met een fysieke beperking, verstandelijke beperking, medische ziekte, prematuriteit en laag geboortegewicht. ARFID komt vaak samen voor met een angststoornis, stemmingsstoornis, autismespectrumstoornis of ADHD, maar kan ook alleen voorkomen (Kerwin, 1999). Uit een recente studie onder 1.444 Zwitserse basisschoolkinderen (8-13 jaar) bleek dat 3,2\% van hen aan de criteria voor ARFID voldeed (Kurz, van Dyck, Dremmel, Munsch, \& Hilbert, 2015). In gespecialiseerde klinieken voor eetstoornissen voor kinderen en adolescenten wordt het vóórkomen van ARFID geschat op 5-14\% (Eddy et al., 2015; Fisher et al., 2014; Ornstein et al., 2013). Van de Amerikaanse volwassenen die aan een online vragenlijststudie meededen herkenden circa 3\% zich in de criteria van ARFID (Zickgraf, Franklin, \& Rozin, 2016).

\section{Diagnostiek en behandeling}

Omdat de diagnose ARFID relatief nieuw is, zijn diagnostische methoden en behandelstudies nog dun gezaaid. Voor klassieke eetstoornissen hebben we als diagnostische gouden standaard de Eating Disorder Examination (EDE), een instrument dat door Chris Fairburn uit Oxford werd ontwikkeld (Fairburn, Cooper, \& O'Connor, 2008). Dit semigestructureerde interview wordt afgenomen door een psycholoog en beoogt de specifieke eetstoornispsychopathologie te bepalen. Voor het afnemen van de EDE dient men getraind te zijn: het is namelijk van belang dat, wanneer verschillende psychologen dezelfde patiënt zouden interviewen, zij dezelfde scores geven aan de verschillende klachten.

Rachel Bryant-Waugh en collega's (2019) hebben een vergelijkbaar interview ontwikkeld voor onder andere ARFID: de Pica, ARFID, and Rumination Disorder Interview (PARDI). Onlangs hebben Renate Neimeijer en ikzelf (2018) dit interview in het Nederlands vertaald om het te kunnen gebruiken in Nederland en Vlaanderen en op termijn normscores te kunnen rapporteren. Het is bijvoorbeeld interessant om te weten hoe vaak ARFID, inclusief de subtypen, in de algemene bevolking voorkomt, of hoe mensen in de algemene bevolking op dit interview scoren, in vergelijking met mensen die ARFID hebben. In de eind 2017 gepubliceerde Zorgstandaard eetstoornissen (www.ggzstandaarden.nl/zorgstandaarden/eetstoornissen), waaraan ik deelnam als werkgroeplid, vermeldden wij de volgende tekst: ' $\mathrm{Er}$ is (nog) geen protocollaire behandelvorm voor de behandeling van kinderen, jongeren en volwassenen met ARFID. In gespecialiseerde centra is wel ervaring met een geprotocolleerde handelwijze om kinderen weer te laten eten. Behandeling (na eventuele medische interventies) vindt dan plaats volgens gedragstherapeutische principes, waarbij geleidelijk toenemende exposure (blootstelling) aan het vermeden voedsel wordt toegepast in combinatie met responspreventie (er mag niet vermeden worden te eten).' 
Een voorbeeld hiervan in ons eigen behandelcentrum SeysCentra is het door Daniel Seys en Pieter Duker ontwikkelde SLIK-programma voor jonge kinderen (Dumont et al., in druk; Seys et al., 2014). Voor andere eetstoornissen geldt cognitieve gedragstherapie (CGT) als een bewezen effectieve therapie (Hay et al., 2014; Murphy, Straebler, Cooper, \& Fairburn, 2010; National Institute for Health and Care Excellence, 2017; www.ggzstandaarden.nl/zorgstandaarden/eetstoornissen). Omdat eetstoornissen - en ARFID in het bijzonder - vaak samengaan met angst (Pallister \& Waller, 2008; Swinbourne \& Touyz, 2007), lijkt het aannemelijk om ARFID te behandelen met technieken die ook ingezet worden bij angststoornissen. Ook voor angststoornissen geldt dat CGT de eerste keuze van behandeling is.

Binnen CGT-programma's zijn exposure (de patiënt blootstellen aan waar hij bang voor is) en gedragsexperimenten goede technieken om angst en catastrofaal denken te reduceren. Michelle Craske en collega's (2008; Craske, Treanor, Conway, Zbozinek, \& Vervliet, 2014) suggereren dat exposuretherapie werkt door het schenden van verwachtingen, en dat niet angstafname maar ontkrachting van verwachtingen het belangrijkste doel moet zijn in de behandeling.

Ik wil dit illustreren met een voorbeeld. Kijkt u eens goed naar deze foto. Wat gaat er door $u$ heen als ik $u$ zou vragen deze sprinkhanen op te eten? Welke verwachtingen hebt u en hoe sterk gelooft u dat deze waar zijn?Maakt u voor uzelf maar af: "Als ik deze sprinkhaan eet, dan .....".

Mogelijke antwoorden zouden kunnen zijn: "dan zal ik stikken”, “dan zal ik deze niet kunnen verdragen (ik MOET hem uitspugen)", of "dan zal ik gek worden". Scoort u voor zichzelf ook even hoe sterk dat geloofwaardig is (op een schaal van 0-100).

$U$ hebt zich zojuist kort verplaatst in een patiënt met ARFID die ofwel bang is, ofwel walgt van het hem of haar voorgeschotelde voedsel.

Toegepast op ARFID zou exposure aan de angstige situatie (dat wil zeggen: het eten van het gevreesde voedsel) effectief zijn zodra de nieuwe associatie (bijvoorbeeld 'ik zal niet stikken in dit voedsel') sterker wordt dan de oude associatie ('ik zal stikken als ik dit voedsel eet'). Tijdens de exposure is het van belang dat patiënten een mismatch ervaren tussen hun verwachtingen (over wat zou kunnen gebeuren) en de uitkomst (wat daadwerkelijk gebeurt). Hiertoe is het van belang om vóór de start van de exposure de specifieke verwachtingen van elke patiënt in kaart te brengen en de geloofwaardigheid ervan te registreren. Wij menen overigens dat exposure deze mismatch niet alleen kan bewerkstelligen bij ARFID van het subtype 3 (situaties die angst opwekken), maar ook kan plaatsvinden bij ARFID van subtype 1 (snel vol zitten, geen interesse in eten) of van subtype 2 (moeite met de sensorische eigenschappen van het voedsel). In de praktijk betekent dit dat de verwachtingen betrekking kunnen hebben op het al dan niet uitbreiden van de hoeveelheid voeding ('Ik kan geen grotere portie aan', 'Mijn maag zal dat niet kunnen verdragen', 'Ik word dan misselijk of ziek') of van de variatie in voeding ('Ik kan een andere textuur niet verdragen', 'Ik móét het gewoon uitspugen'). 
Voor adolescenten hebben we een CGT-programma ontwikkeld waarin deze nieuwe exposure-principes centraal staan. Dit is onlangs getoetst in een case-serie van 11 patiënten. De resultaten zijn veelbelovend en onlangs gepubliceerd (Dumont, Jansen, Kroes, de Haan, \& Mulkens, 2019). Met kleine aanpassingen verwachten we dit behandelprogramma ook voor volwassenen te kunnen gebruiken. Voor sensorisch gevoelige patiënten zou aan de standaard exposure een extra training toegevoegd kunnen worden waarbij blootstelling aan nieuwe texturen centraal staat, bijvoorbeeld ook met de handen. Collega's van de Universiteit Maastricht (bijvoorbeeld: Havermans \& Jansen, 2007; Nederkoorn, Jansen, \& Havermans, 2015; Werthmann et al., 2015) hebben op dit terrein interessante ontdekkingen gedaan die we kunnen gebruiken in de behandeling. Daarnaast zouden mensen met ARFID best weleens 50 of meer proefmomenten nodig kunnen hebben - in tegenstelling tot de eerdergenoemde zeven proefmomenten voor mensen zonder eetproblemen - voordat ze nieuw eten in hun voedingspatroon durven toe te laten. Inmiddels is men op allerlei plaatsen in de wereld gestart om CGT-behandelingen voor ARFID te toetsen. Een goed voorbeeld is het zojuist uitgebrachte behandelprotocol van Jennifer Thomas en Kamryn Eddy (2019) uit Boston. Zij toetsen momenteel in een grote studie of hun aanpak voor de diverse subtypen hout snijdt.

Voor ARFID-patiënten bij wie zich een traumatische gebeurtenis heeft voorgedaan, zou eye movement desensitization and reprocessing (EMDR) - een methode afkomstig uit de traumabehandeling - een veelbelovende aanvulling op CGT kunnen zijn (Beer, 2006; de Roos \& de Jongh, 2006). Dit is iets wat we graag willen onderzoeken. Vrijwel alle kinderen (die op jonge leeftijd worden aangemeld) hebben namelijk een verleden met medische onderzoeken, sondevoeding of een ingrijpende gebeurtenis. Ook een deel van de oudere kinderen of volwassenen die met ARFID worden aangemeld hebben een traumatische ervaring meegemaakt, zoals in de casus Ria.

\section{Therapeutische dwaling}

Zoals gezegd is CGT wereldwijd de eerstekeuzebehandeling voor angst- en eetstoornissen, en daarmee ook voor ARFID. Er zijn goede, bewezen effectieve CGT-protocollen beschikbaar. Uit onderzoek van onder anderen Glenn Waller en collega's (Waller, Stringer, \& Meyer, 2012; Waller \& Turner, 2016) komt echter naar voren dat die protocollen lang niet altijd gevolgd worden. En ook dat (in CGT getrainde) therapeuten regelmatig bewezen ineffectieve interventies inzetten. Onlangs deden wij een studie naar 'therapeutische dwaling' bij de behandeling van mensen met eetstoornissen (Mulkens, de Vos, de Graaff, \& Waller, 2018). Doel was om de studie van Waller te repliceren en uit te breiden met enkele nieuwe variabelen. Voor deze studie werden gegevens geanalyseerd van 139 Nederlandse therapeuten, die via diverse kanalen waren opgeroepen om deel te nemen. De respondenten waren allen werkzaam in het veld van eetstoornissen en maakten gebruik van CGT in de behandeling. Zij vulden online een enquête in. Hierin werd gevraagd naar het gebruik van specifieke technieken in de behandeling van eetstoornissen, hun overtuigingen (zoals over het belang van de therapeutische relatie en gebruik van motiveringstechnieken), angst en persoonlijkheid. 
In overeenstemming met eerder onderzoek kwam naar voren dat therapeuten minder effectief bewezen technieken inzetten dan verwacht mocht worden. Alhoewel $83 \%$ van de respondenten aangaf gebruik te maken van een CGT-protocol in de behandeling, bleken niet alle effectieve technieken systematisch te worden ingezet. Veel van de kerntechnieken van CGT bij eetstoornissen, zoals exposure, eetdagboeken en cognitieve herstructurering, werden door slechts $40 \%$ van de respondenten ingezet. Minder dan $30 \%$ bleek patiënten bij elke afspraak te wegen en 73\% maakte gebruik van motiverende gespreksvoering voor de start van de behandeling, terwijl dit geen bewezen meerwaarde heeft.

Hoe kan die therapeutische dwaling verklaard worden? Wij vonden een aantal interessante correlaties. Zo bleek dat therapeuten met een sterk geloof in de kracht van de therapeutische relatie minder geneigd waren om een breed scala aan effectieve CGT-technieken in te zetten. Ook het angstniveau van therapeuten zelf bleek een rol te spelen: therapeuten die hoger scoorden op een angstvragenlijst waren minder geneigd om gedragstechnieken met onzekere uitkomsten in te zetten, zoals exposure en gedragsexperimenten. Deze bevindingen hebben belangrijke implicaties voor de opleiding en supervisie van therapeuten. De resultaten suggereren dat het vergroten van de competentie van therapeuten niet alleen een kwestie is van training in vaardigheden en kerntechnieken, maar dat er ook aandacht zal moeten zijn voor factoren die ertoe leiden dat therapeuten deze vaardigheden niet inzetten, zoals hun angst en overtuigingen. Het is belangrijk dat therapeuten eraan herinnerd worden dat gedragsverandering bij eetstoornissen niet tot stand komt door een goede therapeutische relatie, maar dat het juist andersom werkt: de relatie met de patiënt verbetert door gedragsverandering in het beginstadium van de behandeling (Graves et al., 2017). Daarom is het getrouw inzetten van gedragstechnieken zo belangrijk. Helaas neemt cognitieve gedragstherapie in handboeken over eetstoornissen relatief weinig plaats in. Met deze rede hoop ik niet alleen ARFID, maar ook het belang van het goed uitoefenen van CGT onder de aandacht te hebben gebracht.

\section{Conclusies en aanbevelingen}

De volgende conclusies en aanbevelingen volgen uit mijn betoog:

1. Er bestaat een voedings- of eetstoornis met een nieuwe naam: ARFID.

2. Laten we deze naam nu ook gaan gebruiken: niet alleen in de psychologie of psychiatrie, maar ook in de geneeskunde.

3. Deze voedings- of eetstoornis heeft vele gezichten.

4. Gebruik van diagnostische methoden en kennis van alle verschijningsvormen van ARFID zal ertoe leiden dat meer patiënten tijdig worden herkend en dat zij de boot naar een juiste behandeling niet missen.

5. Het goede nieuws is: we hebben al de beschikking over effectieve behandelmethoden voor angst- en eetstoornissen die goed toepasbaar zijn op ARFID.

6. Wel moeten we ervoor waken dat we als therapeuten niet op drift raken en zorgen dat we de principes uit de CGT blijven gebruiken. Supervisoren dienen hierop alert te zijn bij hun supervisanten. 


\section{Wat ga ik hier zelf aan doen?}

Als doorgewinterde en geschoolde cognitief gedragstherapeut wil ik - naast ARFID - ook de CGTbehandeling breed uitventen. Ook al is er nog veel ruimte voor verbetering van ons behandelaanbod, CGT is op dit moment het beste wat we te bieden hebben.

Voor kinderen hebben we in onze regio al diverse behandelplekken, waaronder SeysCentra. Voor volwassenen is er echter nog niets. Ik ben vanuit mijn leerstoel voornemens om het behandelaanbod van CGT voor ARFID bij volwassenen op te zetten en uit te breiden. Hiertoe worden nu voorzichtige stappen gezet met de collega's van de afdeling eetstoornissen in het MUMC.

Daarnaast ben ik kartrekker van de zorglijn eetstoornissen binnen het Hersen Zenuw Centrum. We omschrijven de zorglijn eetstoornissen en de raakvlakken met andere zorglijnen en beschrijven onze ambities op het snijvlak met de diverse onderzoekslijnen. Een heel interessante klus.

Op het gebied van diagnostiek werk ik samen met Renate Neimeijer, Klaske Glashouwer en Rachel BryantWaugh, en daarnaast de Vlaamse collega's Lien Goossens en Caroline Braet, om de PARDI in NL taalgebied uit te rollen en onderzoek naar de prevalentie van ARFID te doen.

In de traditie van Daniël Seys en Pieter Duker ga ik door met n=1 studies i.p.v. grote RCT's. En ga ik door met het onderzoek naar ARFID binnen SeysCentra, dat nu 4 locaties heeft. Met SeysCentra-collega Bibi Huskens wil ik mij bijvoorbeeld verdiepen in de relatie van ARFID met autismespectrumstoornissen en rigiditeit in het algemeen. Sensorische gevoeligheid is ook een onderzoekslijn die ik zal gaan uitbreiden. Als bestuurslid van de Nederlandse Academie voor Eetstoornissen zet ik mij met mijn collega's in voor een goed behandelaanbod voor patiënten en scholingsaanbod voor behandelaren.

Met collega Hermien Elgersma werk ik intensief samen op veel vlakken. Eén daarvan is onze ambitie om goede diagnostiek en behandeling via de ondersteuning met e-learnings overal in NL op peil te brengen. Een subsidie van de VGCT en het PAOSfonds is daarbij zeer welkom gebleken.

\section{Dankwoord}

Ik ben aan het einde van deze rede gekomen. Hartelijk dank dat u vandaag met zovelen naar Maastricht bent gereisd. Omdat u mij en/of de aandacht voor ARFID een warm hart toedraagt.

Een aantal mensen wil ik in het bijzonder bedanken:

Allereerst Marieke van Meerten, directeur van SeysCentra voor haar moed/durf om te investeren in onderzoek en deze leerstoel in te stellen.

De hooggeleerden Nanne de Vries en Albert Scherpbier, Rudolf Ponds, David Linden en Bart Rutten die gastvrij de leerstoel hebben omarmd en mij hebben verwelkomd.

31 jaar geleden kwam ik Gezondheidswetenschappen studeren in Maastricht. Mijn jaarwerkstuk inmiddels heet dit de bachelorthese - ging over Anorexia Nervosa en ik had Anita Jansen als begeleider. Mijn afstudeerwerk, over walging en angst voor spinnen schreef ik bij Peter de Jong en Harald Merckelbach. Mijn promotie over bloosangst voltooide ik bij promotor Marcel van den Hout, en co- 
promotoren Peter de Jong en Susan Bögels. Anita, Peter, Harald, Marcel en Susan: jullie zijn mijn grote voorbeelden en jullie zijn er (bijna) allemaal bij vandaag. Hartelijk dank voor jullie enthousiasme, nieuwsgierigheid en passie voor onderzoek.

In mijn ontwikkeling tot psychotherapeut/cognitief gedragstherapeut heeft Hannie van Genderen een belangrijke rol gespeeld.

Mijn toegewijde SeysCentra-collega's wil ik graag bedanken en in het bijzonder Daniel Seys, Pieter Duker, Eric Dumont, Diana Kroes, Eline de Haan, en Kelly Schmeitz. Cécile Bosch voor alle ondersteuning, vooral voor vandaag.

Mijn nieuwe collega's bij de poli eetstoornissen en bij de afdeling Psychologie en Psychiatrie. Mijn oude vertrouwde collega's bij de faculteit Psychologie en in het bijzonder Jessie Beerthuijzen voor haar hulp bij zoveel dingen.

Alle stagiaires, studenten en promovendi met wie ik momenteel samenwerk: Robin, Lisa, Manouk, Amy, Julia, Eline, Kenny, Yi en Eric.

Mijn ouders en broer Mark: Ik weet dat jullie trots zijn op mij, maar ik ben óók trots op jullie! Lieve Joris, lieve Lieve, jullie moeten allebei de bandavond missen die toevallig op beide scholen vanavond plaatsvindt. Ofschoon je weinig keus had ben ik heel blij dat jullie vandaag toch hier zitten.

Amaury, bedankt voor je geduld, liefde en voor de heerlijke boterhammen, die je elke dag voor mij smeert. Mijn werk is geweldig.

Maar jullie drieën geven mijn leven smaak en kleur.

Overigens, met mijn aversie tegen rabarber is het uiteindelijk goed gekomen. Niet alleen bij oma heb ik talloze proefsessies beleefd, ook later heb ik mijzelf regelmatig aan deze groente blootgesteld. Ik vind rabarber nog steeds niet superlekker, maar kan het nu goed verdragen, soms zelfs waarderen. Ik heb dan wel geen ARFID maar de principes van exposure hebben blijkbaar goed gewerkt.

De tanden in ARFID zijn soms lang. Of ze zijn onderhevig aan erosie, door reflux, kokhalzen of daadwerkelijk overgeven. Of...de tanden zijn stevig, want zij worden gezet in dit eetprobleem en ze laten voorlopig niet meer los!

Ik heb gezegd! 


\section{Literatuur}

American Psychiatric Association (APA). (2000). Diagnostic and statistical manual of mental disorders (Fourth edition) (DSM-IV-TR). Washington, DC: American Psychiatric Association.

American Psychiatric Association (APA). (2013). Diagnostic and statistical manual of mental disorders (Fifth edition) (DSM-5). Washington, DC: American Psychiatric Association.

American Psychiatric Association (APA). (2014). Handboek voor de classificatie van psychische stoornissen (DSM-5). Nederlandse vertaling van Diagnostic and Statistical Manual of Mental Disorders, Fifth Edition. Amsterdam: Boom.

Beer, R. (2006). EMDR in de behandeling van adolescenten met een eetstoornis. Onderweg naar: 'Ik ben goed zoals ik ben'. Kinder- \& Jeugdpsychiatrie, 33, 54-64.

Birch, L. L., \& Marlin, D. W. (1982). I don't like it; I never tried it: Effects of exposure on two-year-old children's food preferences. Appetite: Journal of Intake Research, 3, 353-360.

Bryant-Waugh, R. (2000). Eating disorders in children: An overview. In B. Lask \& R. Bryant-Waugh (Eds.), Anorexia nervosa and related eating disorders in childhood and adolescence (pp. 27-40). Hove, UK: Psychology Press.

Bryant-Waugh, R., Micali, N., Cooke, L., Lawson, E., Eddy, T., Kamryn, J., \& Thomas, J. J. (2019). Development of the Pica, ARFID, and Rumination Disorder Interview, a multi-informant, semistructured interview of feeding disorders across the lifespan: A pilot study for ages 10-22. International Journal of Eating Disorders, 52, 378-387.

Craske, M. G., Kircanski, K., Zelikowski, M., Mystkowsky, J., Chowdhury, N., \& Baker, A. (2008). Optimizing inhibitory learning during exposure therapy. Behaviour Research and Therapy, 46, 5-17.

Craske, M. G., Treanor, M., Conway, C. C., Zbozinek, T., \& Vervliet, B. (2014). Maximizing exposure therapy: An inhibitory learning approach. Behaviour Research and Therapy, 58, 10-23.

de Roos, C., \& de Jongh, A. (2006). Slikken of stikken: EMDR bij kinderen met een slikfobie. Kinder- \& Jeugdpsychiatrie, 33, 83-102.

Dumont, E., Huskens, B., Seys, D., Rensen, H., Duker, P., \& Mulkens, S. (in press). Het SLIK-programma: Behandelprotocol voor de vermijdende/restrictieve voedselinnamestoornis (ARFID) bij jonge kinderen. In C. Braet \& S. Bögels (Eds.), Protocollaire behandelingen voor kinderen en adolescenten met psychische klachten. Amsterdam: Boom.

Dumont, E., Jansen, A., Kroes, D., de Haan, E., \& Mulkens, S. (2019). A new cognitive behaviour therapy for adolescents with avoidant/restrictive food intake disorder (ARFID) in a day treatment setting: A clinical case series. International Journal of Eating Disorders, 52, 447-458.

Eddy, K. T., Thomas, J. J., Hastings, E., Edkins, K., Lamont, E., Nevins, C. M., ... Becker, A. E. (2015). Prevalence of DSM-5 avoidant/restrictive food intake disorder in a pediatric gastroenterology healthcare network. International Journal of Eating Disorders, 48, 464-470. 
Fairburn, C. G., Cooper, Z., \& O'Connor, M. (2008). Eating Disorder Examination (16.0D). In C. G. Fairburn (Ed.), Cognitive behavior therapy and eating disorders. New York: Guilford Press.

Fisher, M. M., Rosen, D. S., Onstein, R. M., Mammel, K. A., Kazman, D. K., Rome, E.S., ... Walsh, T. (2014). Characteristics of avoidant/restrictive food intake disorder: A 'new disorder' in DSM-5. Journal of Adolescent Health, 55, 49-52.

Graves, T. A., Tabri, N., Thompson-Breenner, H., Franko, D. L., Eddy, K.T., Bourion-Bedes, S., ... Thomas, J. J. (2017). A meta-analysis of the relation between therapeutic alliance and treatment outcome in eating disorders. International Journal of Eating Disorders, 50, 323-340.

Havermans, R., \& Jansen, A. (2007). Increasing children's liking of vegetables through flavour-flavour learning. Appetite, 48, 259-262.

Hay, P., Chinn, D., Forbes, D., Madden, S., Newton, R., Sugenor, L., ... Royal Australian and New Zealand College of Psychiatrists (2014). Clinical practice guidelines for the treatment of eating disorders. Australian and New Zealand Journal of Psychiatry, 48, 977-1008.

Hoek, H. W. (2006). Incidence, prevalence and mortality of anorexia nervosa and other eating disorders. Current Opinion in Psychiatry, 19, 389-394.

Horne, P. J., Tapper, K., Lowe, C. F., Hardman, C. A., Jackson, M. C., \& Woolner, J. (2004). Increasing children's fruit and vegetable consumption: A peer-modelling and rewards-based intervention. European Journal of Clinical Nutrition, 58, 1649-1660.

Kerwin, M.E. (1999). Empirically supported treatments in pediatric psychology: Severe feeding problems. Journal of Pediatric Psychology, 24, 193-216.

Kindermann, A., \& Kneepkens, F. (2010). Voedings- en eetproblemen bij jonge kinderen. Praktische Pediatrie, 4, 174-179.

Kurz, S., van Dyck, Z., Dremmel, D., Munsch, S., \& Hilbert, A. (2015). Early-onset restrictive eating disturbances in primary school boys and girls. European Child \& Adolescent Psychiatry, 24, $779-785$

Lask, B., \& Bryant-Waugh, R. (Eds.). (2000). Anorexia nervosa and related eating disorders in childhood and adolescence (Second edition). Hove, UK: Psychology Press.

Levy, Y., Levy, A., Zangen, T., Kornfeld, L., Dalal, Y., Samuel, E., ... Levine, A. (2009). Diagnostic clues for identification of nonorganic vs organic causes of food refusal and poor feeding. Journal of Pediatric Gastroenterology and Nutrition, 48, 355-362.

Lindvall Dahlgren, C., Wisting, L., \& Rø, Ø. (2017). Feeding and eating disorders in the DSM-5 era: A systematic review of prevalence rates in non-clinical male and female samples. Journal of Eating Disorders, 5, 56.

Mayes, L. C., Volkmar, F. R., Hook, S.M., \& Cicchetti, D. (1993). Differentiating pervasive developmental disorder not otherwise specified from autism and language disorders. Journal of Autism and Developmental Disorders, 23, 79-90. 
Mulkens, S., de Vos, C., de Graaff, A., \& Waller, G. (2018). To deliver or not to deliver cognitive behavioral therapy for eating disorders: Replication and extension of our understanding of why therapists fail to do what they should do. Behaviour Research and Therapy, 106, 57-63.

Murphy, R., Straebler, S., Cooper, Z., \& Fairburn, C. G. (2010). Cognitive behavioral therapy for eating disorders. Psychiatric Clinics of North America, 33, 611-627.

National Institute for Health and Care Excellence (NICE). (2017). Eating disorders. Recognition and treatment (NICE Guideline NG 69). Retrieved from www.nice.org.uk/guidance/ng69

Nederkoorn, C., Jansen, A., \& Havermans, R. (2015). Feel your food. The influence of tactile sensitivity on picky eating in children. Appetite, 84, 7-10.

Nederlands Centrum Jeugdgezondheid. (2017). JGZ-Richtlijn Voeding en Eetgedrag. Utrecht: Nederlands Centrum Jeugdgezondheid.

Neimeijer, R., \& Mulkens, S. (2018). The Pica, ARFID en Rumination Disorder Interview (PARDI). Nederlandse geautoriseerde vertaling (Unpublished manuscript).

Ornstein, R. M., Rosen, D. S., Mammel, K. A., Callahan, S. T., Forman, S., Jay, M. S., ... Walsh, B. T. (2013). Distribution of eating disorders in children and adolescents using the proposed DSM-5 criteria for feeding and eating disorders. Journal of Adolescent Health, 53, 303-305.

Pallister, E., \& Waller, G. (2008). Anxiety in the eating disorders: Understanding the overlap. Clinical Psychology Review, 28, 366-386.

Seys, D., Dumont, E., van Meerten, M., Rensen, H., \& Duker, P. (2014). Het SLIK-programma: Behandelprotocol voor ernstige voedselweigering bij jonge kinderen. In C. Braet \& S. Bögels (Eds.), Protocollaire behandeling van psychische klachten. Deel I. Amsterdam: Uitgeverij Boom.

Swinbourne, J. M., \& Touyz, S. W. (2007). The comorbidity of eating disorders and anxiety disorders: A review. European Eating Disorders Review, 15, 253-274.

Thomas, J. J., \& Eddy, K. T. (2019). Cognitive-behavioral therapy for avoidant/restrictive food intake disorder. Children, adolescents, and adults. Cambridge: Cambridge University Press.

Thomas, J. J., Lawson, E. A., Micali, N., Madhusmita, M., Deckersbach, T., \& Eddy, K. T. (2017). Avoidant/restrictive food intake disorder: A three-dimensional model of neurobiology with implications for etiology and treatment. Current Psychiatry Reports, 19, 54.

Waller, G., Stringer, H., \& Meyer, C. (2012). What cognitive behavioral techniques do therapists report using when delivering cognitive behavioral therapy for the eating disorders? Journal of Consulting and Clinical Psychology, 80, 171-175.

Waller, G., \& Turner, H. (2016). Therapist drift redux: Why well-meaning clinicians fail to deliver evidencebased therapy, and how to get back on track. Behavior Research and Therapy, 77, 129-137. 
Werthmann, J., Jansen, A., Havermans, R., Nederkoorn, C., Kremers, S., \& Roefs, A. (2015). Bits and pieces. Food texture influences food acceptance in young children. Appetite, 84, 181-187.

Zero to Three (2005). DC:0-3R: Diagnostic classification of mental health and developmental disorders of infancy and early childhood (Revised edition). Washington, DC: Author.

Zero to Three (2016). DC:0-5: Diagnostic classification of mental health and developmental disorders of infancy and early childhood. Washington, DC: Author.

Zickgraf, H. F., Franklin, M. E., \& Rozin, P. (2016). Adult picky eaters with symptoms of avoidant/restrictive food intake disorder: Comparable distress and comorbidity but different eating behaviors compared to those with disordered eating symptoms. Journal of Eating Disorders, 4, 26. 